\title{
Between rhetoric and reality: the relevance of substantive equality approach to addressing gender inequality in Mozambique
}

\author{
Ebenezer Durojaye \\ Dullah Omar Institute, University of the Western Cape, South Africa
}

\begin{abstract}
The purpose of this article is to examine the socio-cultural challenges that continue to limit women's enjoyment of their fundamental rights and freedoms in Mozambique. In this regard, this article focuses on three areas of gender inequality - denial of inheritance rights, sexual violence and early/ child marriage-in the country. In addition, the article, using a substantive equality approach, critically examines whether the steps and measures taken by the government of Mozambique to address gender inequality are consistent with its obligations under international human rights law. For the purpose of this analysis, the article focuses on Mozambique's obligations under the Convention on the Elimination of All forms of Discrimination against Women (CEDAW) and the Protocol to the African Charter on the Rights of Women (African Women's Protocol). The article concludes by making suggestions on how Mozambique can better safeguard the rights of women and improve their status.
\end{abstract}

Key words: gender inequality, human rights, socio-cultural practices, Mozambique

\section{Introduction}

Historically, women have been subjected to all forms of discrimination and human rights abuses. This is often due to structural asymmetry and stereotypes rooted in patriarchy. Thus, women have often been treated as less important compared to their male counterparts. Even at the international level, the evolution of international law, including human rights law, did not accord women the recognition they deserve (Charlesworth et al., 1991:613). Gender inequality and discriminatory practices against women tend to undermine their fundamental rights and freedoms, including their social well-being and sexual and reproductive health and rights. In many African countries gender inequality is pronounced and often the norm rather than the exception in the daily lives of women and girls. Socio-cultural practices and religious tenets often combine to elevate men above women and suppress women's sexual autonomy (Binion 1995: 509; Banda 2005). The consequence of this is the denial of access to essential amenities to enable women to lead a dignified life. It should be noted that since the I9gos, the international community has 
made significant efforts to address gender inequality and improve the status of women worldwide. During this period, two important UN conferences - the International Conference on Population and Development (ICPD) ${ }^{\mathrm{I}}$ and the Fourth World Conference on Women (Beijing Platform) ${ }^{2}$ - took place. These conferences emphasize the need for states to promote and protect the human rights of women, including their sexual and reproductive health and rights. ${ }^{3}$ They also affirm that gender stereotypes and harmful cultural practices are inimical to women's enjoyment of their fundamental rights. Prior to these conferences, the United Nations in 1979 adopted the Convention on the Elimination of All Forms of Discrimination against Women (CEDAW), ${ }^{4}$ the first international human rights instrument specifically dealing with women's rights. The instrument is often referred to as the International Bill of Women's Rights.

More recently, African governments adopted the Protocol to the African Charter on the Rights of Women (African Women's Protocol), which contains elaborate and progressive provisions protecting the fundamental rights of women. Due to its comprehensiveness and the nature of rights protected, the African Women's Protocol is often regarded as one of the most radical human rights instruments on women's rights (Durojaye 2008: 42; Mukasa 2008). Incidentally, the African Women's Protocol was adopted during the African Union meeting in Maputo in 2003. Hence, it is sometimes referred to as the Maputo Protocol. Mozambique has ratified both the CEDAW and the African Women's Protocol. The purpose of this article is to examine the socio-cultural challenges that continue to limit women's enjoyment of their fundamental rights and freedoms in Mozambique. In this regard, this article focuses on three areas of gender inequalitydenial of inheritance rights, sexual violence and early/child marriage-in the country. In addition, the article critically examines whether the steps and measures taken by the government of Mozambique to address gender inequality are consistent with its obligations under international human rights law. For the purpose of this analysis, the article focuses on Mozambique's obligations under CEDAW and the African Women's Protocol. The article concludes by making suggestions on how Mozambique can better safeguard the rights of women and improve their status.

\section{Understanding the socio-political structure of Mozambique}

Mozambique, which gained independence from Portugal in 1975 , is endowed with rich and extensive natural resources. The country's economy is based largely on agriculture, but with a growing industrial base in the areas of food and beverages, chemical manufacturing, aluminium and petroleum production (IMF 20II). In addition, the country's tourism sector is also rising. The official language of Mozambique is Portuguese, (1994); Fourth World Conference on Women (FWCW) Beijing held on 15 September 1995 A/CONF.177/20.

2 Fourth World Conference on Women (FWCW) Beijing held on 15 September 1995 A/CONF.177/20.

3 Ibid para 7.8.

4 Convention on the Elimination of All Forms of Discrimination Against Women GA Res 54/180 UN GAOR 34th Session Supp. No 46 UN Doc A/34/46 1980. Full stop after each entry. 
with roughly half of the population speaking it as a second language and a few as a first language. Local languages widely spoken include Swahili, Makhuwa, and Sena. The largest religion in Mozambique is Christianity, with significant Muslim and African traditional religious minorities. Mozambique is a member of the African Union, Commonwealth of Nations, the Community of Portuguese Language Countries, the Latin Union, Organisation of Islamic Cooperation, Southern African Development Community (SADC) and La Francophonie. In addition to ratifying the CEDAW and African Women's Protocol, Mozambique has also ratified other human rights instruments such as the African Charter on Human and Peoples' Rights, the Convention on the Rights of the Child and the Convention on the Rights of Persons with Disabilities. It should be noted that the African Women's Protocol has been incorporated into Mozambican law through the National Assembly's Resolution No 28/2005 of ${ }_{3} 3$ December 2005.

The Third National Poverty Assessment report indicates that $54.7 \%$ of the population in Mozambique lives below the poverty line (Ministry of Planning and Development: National Directorate of Studies and Analysis 2010). After an impressive decrease of $15.3 \%$ between 1997 and 2002 (from $69.4 \%$ to $54.1 \%$ ), recent statistics would seem to show stagnation in poverty reduction at least in terms of consumption (Mauesse and Cunha 20r1:319). Indicators to measure human development in the country, which include access to education, access to health care services, particularly in rural areas and household ownership of durable goods and housing quality, show that some progress has been made over the years. For instance, the proportion of the population having access to education increased from about $30 \%$ in 2000 to around $38 \%$ in $2008 / 9$ (IMF 201I: 4). Also, there was a significant decrease in the percentage of illiterate women in the country from about $54 \%$ in $2002 / 3$ to $40 \%$ in $2008 / 9$ (IMF 2011 : 4 ).

Life expectancy improved by 7 years from 43 in 1990 to 50 in 2011 (Mausse and Cunha, 2011:319). Conversely, the percentage of proportion of population with access to health unit within 45 minutes increased from $55 \%$ in $2002 / 3$ to $65 \%$ in $2008 / 9$ (IMF 20II). This improvement is more pronounced in rural areas than in urban areas. Within the same period, infant mortality dropped from 245.3 deaths per 1000 live births in 1997 to 138 in 2008 . In the same vein, the maternal mortality rates decreased significantly from 652 to 500 deaths per 100,000 live births between 1997 and 2007(IMF, 2011).

Despite progress, however, challenges remain regarding the poverty situation in terms of geographical distribution and gender inequality. Reports indicate that poverty affects those in rural areas more than urban areas, while women, children and the elderly remain the worst affected by poverty in the country. For instance, the Third National Assessment report has shown that disparity exists in levels of poverty across the regions - rural Northern region experience a fall of about $13 \%$ to $46 \%$, urban and rural South experience a fall of about 7 to $10 \%$ while poverty levels in the Central region increased by $16 \%$ in rural and $7 \%$ in urban areas (Ministry of Planning and Development, 2010: 24). The survey further shows that the poverty incidence is lowest in Niassa, Maputo City and Cabo Delgado (at 32, 36 and $37 \%$, respectively), followed by Tete (42\%) and Nampula (55\%) (Ministry of Planning and Development: National Directorate of Studies and 
Analysis, 2010: 24). The situation in Maputo City is quite revealing and strange as the poverty level is almost as high as other parts of the country. This may be contrasted to the situation in other African countries where the capital is always better off than other cities. Also, while the poverty level for urban area is about $50 \%$ that of rural areas is $57 \%$. The number of people below the poverty line increased from 9.9 million to about 12 million people, due to the growth of the population by 3 million between 2002/03 and 2008/09 (Ministry of Planning and Development: National Directorate of Studies and Analysis, 2010: 25).

\section{The principle of non-discrimination and equality}

The term 'equality' does not give credence to universally acceptable definition. However, it has been recognised that equality is tantamount to non-discrimination; hence an act of discrimination will lead to the violation of rights to equality (Shalev, 2000: 39). The principle of non-discrimination is well recognised in virtually all human rights instruments. Article 7 of the Universal Declaration on Human Rights provides that 'All are equal before the law and are entitled without any discrimination to equal protection of the law. All are entitled to equal protection against any discrimination in violation of this Declaration and against any incitement to such discrimination.' 5 In the same vein, article 2 of the African Charter prohibits discriminatory practices on various grounds including sex, race, religion or other status. Also, article 3 guarantees to every individual the right to equality and equal protection of the law.

Often a distinction is made between formal and substantive equality. The former implies that individuals are treated in the same manner regardless of their socio-economic situations. In essence, formal equality is only interested in treating men and women alike, irrespective of whether they are treated equally badly or equally well' (Freedman, 1996: 202).The formal approach to equality 'embodies a notion of procedural justice', which does not lead to a particular outcome (Barnnard and Hepple, 2000: 566 ). In other words, formal equality is often blind to existing structural differences that exist in a society and that may predispose some groups to disadvantage. While formal equality aims at 'equalisation of rights' in reality it tends to deepen inequality in society.

On the other hand, substantive equality treats individuals equally, paying attention to their peculiar circumstances. It strives at creating a level playing field for all irrespective of their socioeconomic backgrounds, gender or race. Friedman (1999: para 3.12) puts it succinctly, substantive equality 'aims to equalise the starting point'. Generally, a substantive approach to equality is founded on the core value of accommodating people's differences with the aim of achieving equality of outcome. Substantive equality is said to aim at realising equality of result and equality of opportunity. In essence, substantive equality is concerned with achieving an egalitarian society. Sometimes realising equality may mean treating those different the same and in some situations it may mean treating those who are different differently. A good illustration of the notion of substantive equality is contained in 
the opinion of Judge Tinaka of the International Court of Justice in the South West African case, where he notes as follows: ${ }^{6}$

The principle of equality before the law does not mean... absolute equality, namely the equal treatment of men without regard to individual, concrete circumstances, but it means... relative equality, namely the principle to treat equally what are equal and unequally what are unequal... To treat unequal matters differently according to their inequality is not only permitted but required.

From a feminist point of view, Minow (1988: 47) asserts that 'Equality requires same or different treatment, depending on the circumstances and the position of the individual in relation to his or her group-based systemic disadvantage'. This reasoning tallies with the notion of substantive equality. Although not all discrimination amounts to violation of rights, adverse discrimination, which occurs when a person is being treated unfairly, is unjustifiable at law (Gruskin and Tarantola, 2001: 314). A substantive equality approach aims at addressing structural and entrenched disadvantage in society, and at the same time, aspires to maximize human development (Albertyn and Goldblatt 1998). Albertyn and Freeman (2015: 430) have identified a four-dimensional framework for substantive equality which must aim at addressing stigma, prejudice and violence; redressing socioeconomic disadvantage; facilitating participation; and valuing and accommodating difference through structural change. Albertyn and Goldblatt (1998: 250) have argued that committing to substantive equality requires the examination of the context of an alleged rights violation and its relationship to systemic forms of domination within a society. Unlike formal equality, which does not recognise personal differences, substantive equality recognises such personal differences and seeks to adopt a pragmatic approach to accommodate them.

International and regional human rights instruments specifically relating to women would seem to have affirmed the notion of substantive equality. For instance, CEDAW defines discrimination against women broadly to include:

"[A]ny distinction, exclusion or restriction made on the basis of sex which has the effect or purpose of impairing or nullifying the recognition, enjoyment or exercise by women, irrespective of their marital status, on a basis of equality of men and women, of human rights and fundamental freedoms in the political, economic, social, cultural, civil or any other field".?

States parties to the treaty are, therefore, enjoined to take steps and measures to eliminate discrimination against women within their territories. In a similar vein, the African Women's Protocol requires states to remove practices that discriminate against women and urges states parties to take all appropriate steps to eliminate social and cul- 
tural patterns and practices that are discriminatory to women. ${ }^{8}$ It draws extensively from CEDAW in providing a broad definition of discrimination against women. ${ }^{9}$

More importantly, the Protocol in article 5 urges African governments to take appropriate measures including creation of public awareness on harmful cultural practices, adoption of appropriate legislation to address such practices, provision of support to women who are victims of harmful cultural practices and protection of women at risk of harmful cultural practices. It is clear from these provisions that both CEDAW and the African Women's Protocol aim at achieving substantive notion of equality. In addition to these women-specific human right instruments, freedom from discrimination is recognised in other human rights instruments. For instance, article 26 of the International Covenant on Civil and Political Rights (UN I966) guarantees the right to equality before the law and freedom from discrimination. The Human Rights Council in its General Comment 28 (1989: para 12 ) has explained that 'Non-discrimination together with equality before the law and equal protection of the law without discrimination constitutes a basic and general principle relating to the protection of human rights". In Nahlik v Austria ${ }^{10}$ the Committee explains that articles 2 and 26 of the ICCPR obligate states to ensure that all individuals within its territory and subject to its jurisdiction are free from discriminatory practices, whether perpetrated in private or public sphere.

Under the African Charter, article 2 provides that everyone is equal before the law and that no one should be discriminated against on grounds such as gender, religion, political beliefs or other status. Article 3 similarly guarantees to every individual the right to equality and equal protection of the law. The African Commission on Human and Peoples' Rights in Purohit and Moore $v$ The Gambia ${ }^{\text {II }}$ has noted as follows:

Article 2 lays down a principle that is essential to the spirit of the African Charter and is therefore necessary in eradicating discrimination in all its guises, while article 3 is important because it guarantees fair and just treatment of individuals within a legal system of a given country. These provisions are non-derogable and therefore must be respected in all circumstances in order for anyone to enjoy all the rights provided under the African Charter.

This statement summarises the importance of realising the notion of substantive equality in any society. It should be noted that the concept of equality is recognised under the Constitution of Mozambique. Article 36 of the Constitution guarantees the right to equality of men and women in all domains of economic, social, political and cultural life. ${ }^{12}$ The extent to which this provision has been applied to protect women from discriminatory practices is discussed below.

8 See art 2 of the African Women's Protocol adopted by the 2nd Ordinary Session of the African Union General Assembly in 2003 in Maputo, Mozambique Maputo CAB/LEG/66.6 (2003), which drew its inspiration from art 2 of CEDAW.

9 See art 1 of the African Women's Protocol.

Io Communication No 608/1995. 22 July 1996. CCPR/C/57/D/608/1995.

II Communication 241/200I (2003) AHRLR 96 (ACHPR 2003).

I2 Constitution of the Republic of Mozambique 2004. 


\section{Some discriminatory practices that perpetuate gender inequality in Mozambique}

In 2015, Mozambique's Human Development Index was 0.416 , ranking the country at I 80 out of 188 countries (UNDP 2015). Equally, the country's Gender Inequality Index was given the score of 0.591 , placing it at 135 out of 188 countries with data. Also, in 2015, the Global Gap Report ranked Mozambique 126 out of 145 countries, with a score of 0.637 with o representing inequality and I representing equality (World Economic Forum 2015). It should be pointed out that the Mozambican government has made important progress in addressing gender inequality, especially in the political sphere. For instance, 8 out of 29 cabinet ministers, five out of 26 deputy ministers, 6 out of 23 permanent secretaries and 3 out of II provincial governors are all women. In addition, while women constitute about $28 \%$ of members of Parliament in 1997 the figure has increased to about $39 \%$ in the current regime, one of the highest in the region. ${ }^{13}$ Commentators such as Sheldon (2002) and Arnfred (2004) have noted that Mozambican society is historically patriarchal in nature and that in traditional settings men have always controlled political powers by ruling over independent chieftainships. This is further supported by the fact that the Council of Elders was essentially made up of village headmen and cult priests. With regard to socio-cultural order, the Bantu culture - both matrilineal north and patrilineal south - are still found to be dominated by men since the most important men in the North were the matrikin (mother's father or brother). While women would seem to be influential at clan levels, royal family, extended family units, they never enjoyed any formal position of power (Tventen 20I1). Even the advent of colonialism did not change the situation as the Portuguese colonialists exhibited patricidal tendencies including male supremacy. Arnfred (2011: 143) has argued that some cultural practices in Mozambique, especially the initiation ceremony, have often been misunderstood and that rather than demeaning women, they are meant to promote their well-being and dignity. According to her, through the initiation ceremony, girls become women, not through physical or biological change, but rather through 'tests, trials, dances, performances and passing-on of secret knowledge' (Arnfred 2011: 145).

At independence, the socialist Frelimo government did attempt to address gender inequality and to empower women in the country. This resulted in positive developments such as women's political representation and employment in state owned firms (Tventen 20II). These developments, however, have not really translated into a better standard of living for Mozambican women. Rather, poverty and inequality have persisted in the country. In addition, cultural practices have continued to subjugate women's rights to those of men. While the government of Mozambique has made significant efforts at advancing the rights of women in the country, women continue to encounter discriminatory practices and human rights violations on a daily basis. ${ }^{14}$ Discriminatory practices against women in the country continue to occur in areas such as early marriage and polygamy.

13 Combined Reports of Mozambique to the African Commission on Human and Peoples' Rights 2014.

14 CEDAW Committee Concluding Observations to Mozambique CEDAW/C/MOZ/CO/2, 2007. 
It should also be noted that Mozambique has one of the highest HIV prevalence rates in the world and women are more affected than their male counterparts (UNAIDS 2014). As noted earlier, Mozambique has ratified international and regional human rights instruments on women such as the Convention on the Elimination of All Forms of Discrimination against Women (CEDAW ratified in 1993) and the Protocol to the African Charter on the Rights of Women (African Women's Protocol ratified in 2005).

These human rights instruments require a pragmatic approach from the government in realising gender equality in the country. Such an approach, as noted above, must coincide with the notion of substantive equality, which must not only aim at de facto but rather de jure equality.

\section{Early/child marriage}

Across the world about 700 million girls are given away in marriage before they celebrate their I8th birthday (UNICEF 2013). One manifestation of gender inequality in Mozambique is the high rate of child or early marriage. This is often referred to as the marriage of girls under 18 . Although by virtue of the Family Law Act of 2004, the marriage age in Mozambique is 18 years, marriage may be authorised from the age of 16 , in the event of pregnancy or with consent of the parents or legal representatives. ${ }^{15}$ Even though consent of both parties to a marriage is essential and while the Family Law Act provides that marriage is a voluntary union, many parents still engage in child marriage under customary law (Namburete 2009). Recent reports have shown an increase in the number of child marriages in the country. According to the United Nations reports, about $48 \%$ of girls between 15 and 19 years of age are married, divorced or widowed in Mozambique (UNFPA and UNICEF 2015). Early marriage is far more common in rural areas, compared to urban areas. While the median age of marriage in urban areas is 19.6 years that of rural areas is I8.2 years. In total, about half a million Mozambican girls aged 20-24 got married before they reach the age of 18 (UNFPA and UNICEF 2015). In 2005, UNICEF reported that $85 \%$ of 15 -19 year old women in a union were in a rural area, compared to $15 \%$ living in an urban area (UNICEF 2005).

According to Nour (2009: 53), the three main reasons driving child marriage include poverty, the need to reinforce social ties and the belief that it offers protection. Early or child marriage can lead to serious repercussions for the health and well-being of the girl-child. Also, children of adolescent mothers are more likely to be malnourished than children of mothers in other age groups. Equally, children of adolescent mothers have a greater likelihood of early death than children of mothers in other age groups (UNFPA and UNICEF 2015). Moreover, early/child marriage is a serious human rights violation as it undermines the right to sexual and reproductive autonomy of the girl child. It should also be noted that when a girl is married off early her opportunity to acquire education and be able to live a dignified life is limited. Indeed, early/child marriage deprives the girl-child the opportunity to be educated and to escape poverty. In addition, studies have

15 United Nations Committee on the Elimination of Discrimination Against Women (2007b), Summary Record of the $784^{\text {th }}$ Meeting, CEDAW/C/SR.784, CEDAW, New York, NY. para 50. 
shown that early/child marriage poses grave health hazards to girls, including early or unplanned pregnancy, virginal fistula and maternal death (Nour 2006; Raj et al. 2009).

During the International Conference on Population and Development and the Fourth World Conference on Women, the international community agreed that women and girls should be allowed to exercise free choices in all matters relating to their sexual and reproductive health. ${ }^{16}$ In particular, it was agreed that women and girls should have the freedom to determine the timing and number of their children. ${ }^{17}$ Both the African Women's Protocol and CEDAW contain provisions that frown upon early/child marriage. Article 6 (a) of the Protocol declares that 'no marriage should take place without the free and full consent of both parties'. The CEDAW Committee (I994) has explained in its General Recommendation 21 on Equality in Marriage and Family that early/child marriage not only erodes the right of women and girls to give full consent to marriage, but also amounts to an act of discrimination..$^{18}$ More importantly, the Committee notes that a woman's right to exercise free choice in marriage is central to her life and dignity and equality as a human being. ${ }^{19}$ Also, the CEDAW Committee in one of its concluding observations to the government of Mozambique has expressed grave concern about the persistence of discriminatory stereotypes, cultural practices and traditions of a patriarchal nature relating to the roles and responsibilities of women and men in the family and in society, as they constitute serious obstacles to women's educational and professional prospects and the enjoyment of their human rights and contribute to the persistence of violence against women. ${ }^{20}$ Furthermore, in its General Comment 31-jointly adopted with the Committee on the Rights of the Child- the CEDAW Committee has noted that:

[t] defined, rights-based and locally-relevant holistic strategy which includes supportive legal and policy measures, including social measures that are combined with a commensurate political commitment and accountability at all levels. ${ }^{21}$

Thus, a substantive equality approach from the Mozambican government requires it to address practices that encourage child marriage, enact appropriate legislation to deal with it and provide free and compulsory education for girls at all level in provinces where the practice is rampant. More importantly, the government should embark on

Report of the International Conference on Population and Development (ICPD) 7, UN Doc A/CONF.171/13 (1994); Fourth World Conference on Women (FWCW) Beijing held on 15 September 1995 A/CONF.177/20.

17 ICPD para 7.8

I8 UN Committee on the Elimination of Discrimination Against Women (CEDAW), CEDAW General Recommendation No. 21: Equality in Marriage and Family Relations, 1994 adopted at the Thirteenth Session A/49/38).

19 General Comment 21 para 16.

20 CEDAW Committee Concluding Observations to Mozambique CEDAW/C/MOZ/CO/2, 2007.

2I UN Committee on Elimination of All Forms of Discrimination against Women (CEDAW) Joint general recommendation/general comment No. 31 of the Committee on the Elimination of Discrimination against Women and No. 18 of the Committee on the Rights of the Child on harmful practices CEDAW/C/GC/3 para 52. 
education or awareness programmes that must address the incidence of child marriage in the country. As noted earlier, the main aim of substantive equality is to correct the historical injustice or disadvantaged suffered by a specific group of people. Given that women and girls have been subjected to discriminatory practices in Mozambique, remedial measures are required to assuage the pains of the past. This must provide succour to women and girls and enable them attain their full potential in life.

\section{Sexual violence and HIVIAIDS}

Due to gender inequality and low status of women, gender-based violence has remained a great threat to women's health and well-being in Mozambique. Commenting on gender inequality in Mozambique, Urdang (1989: 24) has observed as follows:

Patriarchal attitudes are well and alive in Mozambique; empowerment, where it exits, is still something bestowed on women by men and the 'self' for women remains somewhat stifled... Yet the commitment to 'women's concerns' - an increasingly array of items that affect women more particularly than men - too often take the place of a genuine belief in and call for gender struggle. Women's concerns are for the most part though not exclusively-synonymous with women's problems. And problems are regularly taken to mean those that concern women in relation to family.

Gender-based violence may be described as acts of violence against women that are legitimized by stereotypical beliefs and subordinate position of women in society. The UN Declaration on Violence against Women (I993: Para 4) defines violence against women as 'any act of gender-based violence that results in, or is likely to result in, physical, sexual or psychological harm or suffering to women, including threats of such acts, coercion or arbitrary deprivation of liberty, whether occurring in public or in private life.' Gender-based violence, particularly sexual violence, tends to predispose women to health hazards, especially sexually transmitted infections, including HIV/AIDS and unwanted pregnancies. The African Women's Protocol (2003) has echoed this definition by providing that 'Violence against women' means all acts perpetrated against women which cause or could cause them physical, sexual, psychological, and economic harm, including the threat to take such acts...' In addition, sexual violence is a gross violation of a woman's right to dignity, equality and freedom from inhuman and degrading treatment. Gender-based violence is usually as a result of power inequities between men and women at both societal and relationship level often exacerbated by patriarchy (Dunkie et al, 2004: Jewkes et al, 2010; Jewkes and Morrell, 2010).

While it is generally difficult to obtain accurate figures for the numbers of women in Mozambique who experience violence daily, it is believed that one in four women in the country has undergone gender-based violence at least once in her life time (BerghCollier 2007:55). There would seem to be a connection between this high rate of genderbased violence and high HIV prevalence in the country. This is consistent with studies that have shown the link between gender-based violence and HIV prevalence. (Maman 2000: Garcia-Moreno \& Watts 2000; UNAIDS \& WHO 2005). Indeed, a report has noted that 
sexual violence against women is not only harmful to their physical and psychological well-being but may also render them susceptible to sexually transmitted infections, including HIV (Krug et al. 2002).The report further adopts a useful typology of violence in general to include physical violence, sexual violence, psychological violence and deprivation or neglect. Kilpatrick (2004) similarly notes that violence against women is a common phenomenon across the world, which is accompanied by serious physical and mental consequences. Jewkes et al. (2002.148) have defined sexual violence as 'Any sexual act, attempt to obtain a sexual act, unwanted sexual comments or advances, or acts to traffic, or otherwise directed, against person' sexuality using coercion, by any person regardless of their relationship to the victim in any setting, including but not limited to home and work.'

UNAIDS (2014) estimated that $11 \%$ of the population, that is 1.6 million people (distributed amongst $13.1 \%$ of female and $9.2 \%$ of male adults aged $15-49$.), were living with HIV in the country. Women are disproportionately affected accounting for more than $60 \%$ of people living with HIV in the country. This clearly indicates that the HIV epidemic in Mozambique bears a woman's face. Young women are said to be three times more likely to be infected than their male counterparts. While it is difficult to obtain accurate data on violence against women in Mozambique, a study has shown that about $50 \%$ of women interviewed confirm that they have experienced violence (UNIFEM 2007). The study further makes the link between gender-based violence and high HIV prevalence in the country. Sadly, rather than resisting this human rights abuse, most Mozambican women in rural areas have tended to internalise and rationalise gender-based violence. A study conducted in the country shows that $54 \%$ of women aged $15-49$ said that it is justified to be beaten by their husbands/partners for flimsy reasons such as stealing food, arguing, leaving the house without informing him, refusing sex and not looking after the children (Bergh-Collier 2007). Rural women are more accepting of domestic violence than urban women, with $57.5 \%$ of rural women accepting it compared to $48 \%$ of urban women. An interesting aspect of this study reveals that men are less accepting of domestic violence, with only $4 \mathrm{I} .5 \%$ of men aged 15 years and older saying that it is justified to beat one's spouse for the reasons given above (Bergh-Collier 2007).

According to the African Women's Report of 2009 (Economic Commission for Africa 2009), hospital gynaecologists have treated numerous cases of incest and rape of young girls perpetrated by their male relatives and without the knowledge of their parents. A report by the US Department of State (2010) indicates that marital rape is common although unreported, with most families preferring to settle such matters privately through financial settlement rather than through the judicial system. One major problem for women's physical integrity is the widespread nature of attitudes that accept and excuse violence against women. The Demographic and Health Survey (2011) revealed that one third of women in Mozambique had experienced violence in one form or another since the age of 15 . It further revealed that $12 \%$ of women reported being forced to have sex at some point in their lifetime. Furthermore, it is reported that of the women surveyed that have experienced sexual violence, about $58 \%$ of them never reported or 
sought help. Violence against women in all its ramifications not only constitutes an act of discrimination but can also perpetuate the low status of women in society. ${ }^{22}$ In addition, gender-based violence, particularly sexual violence, is a threat to a woman's fundamental rights to freedom, life, dignity, health and liberty.

The Mozambican government has recognised the fight against HIV and AIDS as part of poverty reduction (Institute for Education Development, 2004). There are seven priority areas in the national strategies against HIV and AIDS namely: prevention; advocacy; stigma and discrimination; treatment; mitigation; research; and coordination of the national response (National AIDS Strategic Plan 2005). ${ }^{23}$ The National Strategic AIDS Plan recognizes how gender inequalities increase women's vulnerability and commits to measures such as promoting their access to legal instruments to fight sexual violence. It also lays emphasis on reducing HIV infection among $15-24$ year olds through measures such as improving condom distribution and providing free treatment for sexually transmitted infections. In an attempt to address this serious challenge, the Mozambican government in 2009 enacted Law No 29 on Domestic Violence against Women. The viability of this law to address gender-based violence in the country is discussed below. Suffice to state here that deep inequality and cultural norms continue to expose women to various forms of violence in the country.

The CEDAW Committee has noted in its General Recommendation ig that States have the obligations to enact and implement appropriate laws and policies to address gender-based violence whether in the public or private sphere. In addition, the Committee notes that a state will be held accountable for acts of violence perpetrated against women by individuals in the private sphere if the state fails to adopt appropriate measures to prevent such acts of violence. ${ }^{24}$ Article 4 of the African Women's Protocol enjoins states to adopt laws, policies and programmes that will address gender-based violence whether the violence takes place in private or public. States are also required to adopt other measures including 'legislative, administrative, social and economic measures as may be necessary to ensure the prevention, punishment and eradication of all forms of violence against women.

More importantly, the Protocol enjoins states to adopt a holistic approach towards combating gender-based violence. Such an approach must include but not be limited to the promotion of peace education through curricula and social communication with a view to eradicating elements of cultural practices that exacerbate gender-based violence. It also calls for the establishment of mechanisms to provide information, rehabilitation and reparation for victims of gender-based violence. In one of its recent decisions, the African Commission has noted that gender-based violence constitutes a gross violation of

\footnotetext{
22 UN Committee on the Elimination of Discrimination Against Women (CEDAW), CEDAW General Recommendations Nos. 19 adopted at the Eleventh Session, 1992 Doc. A/47/38.

23 The National Strategic AIDS Plan 2005-2009 quoted in UNFPA 'Report Card on HIV Prevention for Girls and Young Women.

24 General Recommendation I9. para 12.
} 
the fundamental rights of African women. ${ }^{25}$ The Commission adopted a gender-sensitive approach by holding that acts of violence perpetrated by private actors will be imputed to the government if no proactive steps were taken to prevent the violence. This requires that the Mozambican government must take decisive measures with a view to addressing violence against women in the country.

From the foregoing, a substantive equality approach will require the Mozambican government adopt drastic measures that will address the low status of women in the country. This requires the government to establish institutions that will be responsive to victims of gender based violence. Equally, it will be necessary for the government to adopt a pre-emptory approach that will go a long way in preventing violence against women in society. In this regard, civic education and sexual education will need to be introduced in schools at an early stage to equip pupils with knowledge about respect for all individuals regardless of sex, gender or race. In particular, it should address issues such as gender roles as well as emphasize on caring attitudes towards the women and girls. It should also dismantle stereotypical attitudes often exhibited by society towards women and girls as well as address violence in all its ramifications.

\section{Denial of inheritance rights}

As in many other African countries, women continue to encounter discriminatory practices in relation to inheritance rights in Mozambique. Despite the constitutional provision on equality, entrenched customary practices tend to deny women and children right of inheritance in the country. Studies by Save the Children $(2007 ; 2009)$ have documented discriminatory practices against women and children in relation to inheritance rights in Mozambique. According to these studies, cultural practices tend to exclude women and children, especially the girl-child orphaned by AIDS, from inheriting property left behind by their husband or father. One of the studies conducted in about four districts in Mozambique, including Chókwè, in the southern province of Gaza, Bárué and Morrumbala in the central provinces of Manica and Zambézia respectively and Nacala in the northern province of Nampula, highlights the existing tension between statutory law and customary practices in a pluralistic society such as Mozambique.

While on the one hand constitutional provisions and other statutory laws such as the Family Law of 2004 recognise the rights of women and girls to inheritance, on the other hand, customary practices in these districts tend to deny inheritance rights to women and children, especially girls. A report by Save the Children (2007) notes that while about $60 \%$ of those surveyed are of the view that social norms allow men and women to inherit land and money equally, in practice men are more likely to inherit valuable assets such as house and commercial activities compared to women that are often left with cookery, clothing and other insignificant items.

The situation is more precarious for women and girls in predominantly patrilineal communities such as the south and central regions, particularly, Bárué, Morrumbala,

25 Egyptian Initiative for Personal Rights and INTERIGHTS v Egypt Communication,Communication 334/06 decided in 2011. 
and Chókwè. In these communities, while men are seen as heirs to the property of a deceased father, women and girls are merely viewed as temporary guardians of property but are never recognised as having bonafide rights of inheritance. Narrating a personal experience a widow explained thus:

I was living with my husband, Pedro, and my three youngest daughters, when he fell sick. He was sick for a long time, but I'm not sure what he had. He was covered in spots and suffered from diarrhoea that did not stop. I took him both to the traditional healer and the hospital. I gave him the treatment I received from both, but he didn't get better. We didn't talk together about what would happen after his death, but he wrote that all his belongings and land should remain with his children. However, during the funeral proceedings, on the eighth day after my husband's death, while I was at his family home, they took all my livestock - two bulls, two cows, a goat, four chickens, five chicks, our plough, our radio, and his cell phone. (Save the Children 2007: 10)

Also, one of the focus group discussions involving men reveals that women and girls are regarded as minors that should not be allowed to inherit any property left behind by their husband or father. ${ }^{26}$ This situation is not peculiar to Mozambique as studies in other African countries would seem to exemplify similar challenges. For instance, a study conducted in Zambia has found that on average widow-headed households control $35 \%$ less land following their husband's death (Chapoto et al. 2007) Similarly, a study in Namibia has shown that $44 \%$ of widows and orphans lost cattle, while $39 \%$ lost farm equipment (FAO/IP, 2003). It should be borne in mind that denial of inheritance rights to women and girls may further lead to denial of access to economic resources, particularly land, thus perpetuating poverty among women.

Denial of inheritance rights to women and girls is not only contradictory to the equality provision of the Mozambican Constitution and the provision of the Family Law of 2004, it is also inconsistent with the country's obligation under international and regional human rights instruments such as the CEDAW, CRC and the African Women's Protocol. Such a practice can undermine the rights to dignity and non-discrimination of women (Durojaye 2013). Article 21 of the African Women's Protocol imposes obligations on African governments to ensure that their laws and policies recognise women's right to inheritance. In addition, article 2I (2) enjoins African governments to take appropriate measures in order to ensure that women and men shall have the right to inherit, in equitable shares, their parents' properties. As noted earlier, Mozambique has ratified the African Women's Protocol; therefore, it is obligated to comply with its provisions. In addition, the SADC Protocol on Gender condemns discriminatory practices that may impair women from enjoying their fundamental rights. ${ }^{27}$

Although Mozambican courts have yet to address the issue of denial of inheritance right to women, lessons can be drawn from decisions in other countries in the SADC re-

27 See art 20 the SADC Protocol on Gender and Development adopted in 2008. 
gion. For instance, a recent decision of the Court of Appeal in Botswana has condemned such a practice as constituting an act of discrimination and violation of the fundamental rights of women. ${ }^{28} \mathrm{Also}$, in an earlier decision of the South African Constitutional Court in Bhe \& Others $v$ Magistrate Khayelitsha, ${ }^{29}$ it was held that the primogeniture practice that often excludes a female child from inheriting property from her deceased father is discriminatory and inconsistent with the equality clause of the South African Constitution. It is hoped that Mozambican courts will borrow a leaf from these progressive decisions.

In addition to denial of inheritance rights, women and girls are often subjected to harmful cultural practices such as widow inheritance and land grabbing. In most parts of Mozambique it is traditionally believed that a woman should be 'married to another man from her deceased husband's family (Save the Children 2009). While it is claimed that this tradition is aimed at preventing the woman from experiencing poverty, it has implications for the health and dignity of a woman. Such a practice can expose a woman to HIV infection and may also perpetuate the low status of women in society.

In one of its Concluding Observations to the government of Mozambique, the CEDAW Committee has noted with concern that discriminatory provisions still exist in many laws, particularly in relation to the Penal Code and laws governing inheritance, in the country ${ }^{30}$ More importantly, the Committee has expressed grave concern with regard to 'the persistence of discriminatory stereotypes and cultural practices and traditions of a patriarchal nature relating to the roles and responsibilities of women and men in the family and in society, as they constitute serious obstacles to women's educational and professional prospects and the enjoyment of their human rights and contribute to the persistence of violence against women' (para 20). The Committee thus urges the Mozambican government to adopt comprehensive strategies and programmes that will promote cultural change, eliminate gender inequality between men and women and address discriminatory stereotypes regarding the roles of women in society in accordance with articles 2 and 5 of the Convention (para 21). This would seem to coincide with a substantive equality approach.

Furthermore, the African Commission in one of its recent resolutions has noted that laws and cultural practices that deny access to land to women constitute an act of discrimination 2 in contravention of the African Charter and the African Women's Protocol. ${ }^{31}$ The Commission, therefore, urges African governments to ensure that appropriate steps and measures are adopted to address this situation. In particular, states are urged to reform their laws and adopt positive programmes with a view to safeguarding the human rights of women and improving their economic situation in society. This call by the Commission is consistent with substantive equality approach.

Ramantele v Mmusi and Others (CACGB-104-12) [2013] BWCA I).

[2005] (I) BCLR I (CC).

CEDAW Committee Concluding Observations: Mozambique 2007.

Resolution 262 of the African Commission on Human and Peoples' Rights on Access to Land and Women adopted at the 54tht Ordinary Session held in Banjul, The Gambia 2013.
} 
In order for women' to enjoy equal access to inheritance rights, the Mozambican government will need to take positive steps and measures to ensure that this happens. More importantly, there is need for law reforms that will address norms and cultural practices that have historically disadvantaged women. This will entail correcting the existing institutional structure that exacerbates gender inequality. The South African Constitutional Court decision in the Bhe case serves a good example of how a substantive equality approach should be adopted to address the historical disadvantages women encounter in Mozambique.

\section{Legal and institutional framework to address gender inequality in Mozambique}

As noted above, the Constitution of Mozambique, 2004 contains important provisions relating to human rights in general and gender equality in particular. The preamble to the Constitution recognises the plural nature of Mozambique. However, it affirms the need to respect and guarantee fundamental rights of all citizens. One of the fundamental objectives of the Constitution as stipulated in article $I$ is 'the defence and promotion of human rights and of the equality of citizens before the law'. More importantly, Chapter III of the Constitution contains a number of fundamental rights that can be invoked to protect women from discriminatory practices. In this regard, articles 35 and 36 are very important and worth examining. Article 35 provides that all citizens are equal before the law and shall enjoy the same rights and duties irrespective of their colour, race, sex, ethnic origin, place of birth, religion, level of education, social position, the marital status of their parents, their profession or their political preference. Although this provision does not specifically use the word 'gender' the use of the word 'sex' should be broadly interpreted to prevent discriminatory practices against women. Article 36 is more emphatic, it declares that 'men and women are equal before the law in all spheres, including political, economic, social and cultural'. The inclusion of this provision, which is rarely found in most other constitutions in Africa, is to reaffirm the importance the constitution places on gender equality. Indeed, it can be argued that article 36 of the Constitution is consistent with the notion of substantive equality.

Furthermore, article 43 of the Constitution is a unique provision, which provides that the human rights provisions shall be interpreted and integrated in harmony with the Universal Declaration of Human Rights and the African Charter. It is not clear why the drafters limit the interpretation to these two human rights instruments. But it could be argued that all other human rights instruments already ratified by Mozambique should be considered in interpreting the human rights provisions in the Constitution. Thus, the provisions of CEDAW and the African Women's Protocol should be considered by Mozambican courts in interpreting the human rights provisions in Chapter III. In other words, in assessing whether Mozambique has taken adequate measures to address gender inequality, the benchmarks contains in articles 2 of CEDAW and 5 of the African Women's Protocol shall be taken into consideration. The courts in Mozambique are yet to develop its jurisprudence as regard the equality provision of the Constitution. 
In addition to the Constitutional provision, Mozambique has enacted laws and initiated policies that are useful in addressing gender inequality in the country. For example, in 2004 Mozambique adopted the Family law which stipulates that the marriageable age for both boys and girls shall be 18 years. It further provides for equal right between boys and girls in inheritance matters. The law has done away with the designation of 'head of family', which implies that families can now be represented by any of the spouses. Also, in 2007 the Labour Law No 23 was enacted to address gender inequality in employment opportunities. It specifically protects working mothers, by increasing maternity leave from 60 to 90 days, and providing for a specific timetable to child feeding. More importantly, the Law protects women from all forms of sexual harassment in the workplace. Furthermore, in 2009, Law No 29 on Domestic Violence against Women was enacted to protect women from physical and sexual violence in both private and public spheres. Aside punishing acts of violence against women, the law also provides for the rehabilitation of women that have suffered violence. This is a very important provision, which coincides with recent developments at international law. Human Rights Treaty Bodies such as the CEDAW Committee would seem to support the need for rehabilitation of women who have undergone any form of violence.

Additional to the aforementioned laws, the Mozambican government has established relevant institutions and bodies to address gender inequality in the country. For instance, in 2003 the government established the Ministry for Women and Social Action. (MNAS), which replaced the Ministry for Women and Coordination of Social Action (MMCAS) created in 2000. Also, a body within the MNAS known as the National Directorate for Women (DNM) was established. The DNM is responsible for the definition and promotion of diverse programmes designed to provide material support as well as to empower women. Moreover, the DNM is charged with the duty of liaising with civil society organizations and other stakeholders with regard to issues bordering on gender equality. It is equally responsible for coordinating activities and programmes aimed at promoting and responding to gender equality. This important role of the DNM is replicated across the provinces through the Ministry's Provincial Directorate (Bergh-Collier 2007). The DNM comprises two departments, namely; the Department for Women and Family and the Department for Gender and Development. The Department for Women and Family is charged with functions such as designing and implementing policies and programmes on social assistance, especially for vulnerable and marginalised women and providing technical support on issues relating to gender dimension of the HIV/AIDS pandemic. As part of its commitment to addressing gender inequality in the country, in 200 r the Mozambican government created the National Council for the Advancement of women (ConselhoNacionalpara o Avanço da Mulher: CNAM). The composition of CNAM is intended to be as broad as possible and includes ministers and Vice-Ministers, two Civil Society Organisations (CSOs) working for gender equality, one representative of religious organizations, one representative of the trade unions and one representative of the private sector. It is hoped that the CNAM will champion the defence and promotion of human rights as well as the equality of citizens before the law (Bergh-Collier 2007). The 
primary functions of CNAM include promoting and monitoring of government's gender policies, plans and programmes, particularly in relation to the National Plan for the Advancement of Women ((Plano Nacionalpara o Avanço da Mulher: PNAM)) and other National Gender Strategy ((Política de Género e Estratégia de Implementação: PGEI).

Upon the establishment of CNAM in 2006, the Mozambican government adopted a National Gender Policy and Strategy (PGEI). The PGEI addresses pertinent issues relating to gender equality, which include the creation of institutional mechanisms to ensure gender mainstreaming in sectoral plans, economic empowerment, food security, education, reduction of maternal mortality, elimination of violence against women, participation of women in public life and decision-making processes, and the protection of the rights of girl children.

With regard to efforts to address sexual violence and HIV, the Report Card on HIV Prevention for Girls and Young Women summarizes the key progress and opportunities for the government with specific relation to five key areas namely: legal provision, policy provision, and availability of services, accessibility of services and participation and rights. ${ }^{32}$ It also calls for more effective and coordinated efforts at addressing gender-based violence, including spousal rape. Similarly, it calls for specific legislation that would protect the human rights within AIDS-related services to protect confidentiality and prevent discrimination.

\section{Recommendations}

As seen from the above, the Mozambican government has made significant efforts at addressing gender inequality in the country. The government has produced a set of well-designed and well-articulated gender policies over the last decade based on the nation's commitment to gender equality. However, for a number of reasons these efforts are not yielding the desired results, including poor implementation, docile judiciary and deep-rooted cultural practices that continue to perpetuate the low status of women in society. It would seem that the government has not been able to translate the existing laws, policies and institutional framework into action such that it can have a positive impact on addressing gender inequality in the country. Cultural practices and stereotypical attitudes continue to threaten women's social well-being and undermine their fundamental rights and freedoms. This is a clear indication that laws and policies are not enough in themselves to address cultural practices; there is need to complement such steps with other useful strategies such as creating awareness among the people. Experience has shown that attempts by African governments to address harmful cultural practices such as Female Genital Cutting/Mutilation through criminalisation have not yielded the desired results as this practice has continued unabated in the region (Durojaye and Munge 20II). Moreover, criminalisation of FGM/C would seem to have further alienated the people and cast aspersions on their long practiced culture. Consequently, there was resistance and non-compliance to this approach (Durojaye and Munge 20II). The lesson to be drawn 
from this experience is that deep-rooted cultural practices cannot be uprooted merely through laws and policies but rather need to be complemented with other strategies such as education and awareness programmes aimed at behavioural change.

Cultures develop among people and change with time (Terry, 2010). Therefore, from the situation in Mozambique, it is obvious that there is urgent need for education and awareness programmes that will address the existing cultural practices including early/child marriagel and denial of inheritance rights to women. For these awareness programmes to succeed, it is imperative that the government join hands with civil society groups that have established good relationships with people in communities and rural areas. This will go a long way to address deep-rooted cultural practices that often fuel discriminatory practices against women in the country. In addition, it is important that the government introduces sexual education in schools that will prepare young people for the challenges they may encounter in their sexual lives. This will help to address issues such as sexual violence, unwanted sexual acts and negotiating strategies.

The National Policy on HIV/AIDS contains promising provisions to curb the spread of HIV in the country; however, it requires a better and more effective implementation strategy to yield the desired results. Additionally, the government needs to ensure active participation of girls and young women, particularly those from marginalized groups, in national action on HIV and AIDS. It also needs to consistently apply international commitments and rights-based approaches to addressing the AIDS pandemic.

Given the difference in gender roles and economic development between the northern and southern parts of the country, the government will need to adopt various strategies appropriate to each region to address deep inequality and poverty. In line with a substantive equality approach, the government will be required to provide support to women in the northern part of the country that engage in agriculture as a way of addressing poverty and inequality. This should be by way of financial assistance or by subsidizing the work of women farmer in the region.

Moreover, while enrolment in schools among girls has increased over the years, the completion rate remains a great challenge. The Mozambican government will be required to adopt programmes that will support girls in schools in order to ensure that they complete schools in good time. In this regard, waiver of school fees and introduction of feeding programmes will be necessary. This will not only empower girls to lead a healthy life, but will also enhance their opportunities for employment.

While civil society groups in the country are making efforts at stemming the causes of discriminatory practices against women, much more will need to be done. It is important that civil society groups become more involved in monitoring government's efforts to fulfil its obligations under national and international law. For instance, civil society groups should advocate the enactment of relevant laws to promote gender equality and campaign for the repeal of potentially discriminatory laws. In addition to submitting shadow reports to government's reports to treaty monitoring bodies, civil society groups should also ensure that the government meets its reporting obligations to these bodies without delay. Moreover, they should ensure that recommendations of treaty monitoring 
bodies such as the CEDAW to the Mozambican government are properly implemented. More importantly, civil society groups should provide human rights education for judges and lawyers focussing on international human rights standards and principles on gender equality. This will equip judges and magistrates with the means to apply these principles and standards to cases of gender equality in the country.

Also, there is need for civil society groups to be involved in strategic litigation to challenge cultural or stereotypical practices that perpetuate gender inequality in the country. This will help to clarify the nature of the government's obligations under national and international law and ultimately helps in developing jurisprudence on gender equality in the country (Nabaneh 2015).

Because the main essence of substantive equality is not merely to ensure de jure but rather de facto equality, it will be necessary for the Mozambican government establishes an emergency fund to provide support to victims of gender-based violence. As indicated above, such a fund will not only provide financial succour to women that are victims of gender-based violence but will also create an opportunity for them to be self-employed.

\section{Conclusion}

As the international community has recently adopted the Social Development Goals, which include among others gender equality and eradication of poverty, much more is required from the Mozambican government to achieve the goals set out under the SDGs. Entrenched cultural practices and stereotypes continue to perpetuate the low status of women and act as barriers to improving the living conditions of women in society. While the Mozambican government has developed laws, policies and an institutional framework to address gender inequality, poor implementation, and adherence to cultural beliefs and half-hearted commitment from policy makers have continued to militate against the realisation of gender equality in the country. It is necessary for the government to join forces with civil society groups in order to create awareness as regards cultural practices and stereotypes that fuel gender inequality in the country.

\section{References}

Albertyn, C. and Freedman, S. (2015). 'Equality beyond Dignity: Multidimensional Equality and Justice Langa's Judgments'. Acta Juridica I: 430-455.

Albertyn, C. and Goldblatt, B. (1998). 'Facing the Challenge of Transformation: Difficulties in the Development of an indigenous Jurisprudence of Equality' South African Journal on Human Rights I4: 248-276.

Arnfred, S. (2004). 'Conceptions of Gender in Colonial and Post-Colonial Discourses: The Case of Mozambique'. In CODESRIA Gender Series / Gender Activism and Studies in Africa 3: 82-100.

Arnfred, S. (20rr). Sexuality and Gender Politics in Mozambique: Rethinking Gender in Africa. Suffolk: James Curry.

Banda, F. (2005). Women, Law and Human Rights. An African Perspective Oxford: Hart Publishing.

Barnnard, C. and Hepple, B. (2000). Substantive Equality. Cambridge Law Journal 59: 562-585.

Bergh-Collier, E.V. (2007). Towards Gender Equality in Mozambique Sweden: SIDA Binion G (1995) Human Rights: A Feminist Perspective. Human Rights Quarterly 17: 509-526.

Charlesworth, H., Chikin, C. and Wright, S. (1991). Feminist Approaches to International Law. American Journal of International law 85: 613-645. 
Chapoto, A., Jayne, T.S. \& Mason, N. (2007). Security of widows' access to land in the era of HIV/AIDS: Panel survey evidence from Zambia. Food Security Research Project, Working Paper No. 25. Lusaka. 28.

Dunkle, K.L., Jewkes, R.K., Brown, H.C., Gray, G.E., McIntryre, J.A. and Harlow, S.D. (2004). Genderbased violence relationship power and risk of HIV infection in women attending antenatal Clinics in South Africa. Lancet 363:1415-21.

Durojaye, E. (2008). Addressing Human Rights Concerns raised by Mandatory HIV Testing of Pregnant Women through the Protocol to the African Charter on the Rights of Women. Journal of African Law 52: 42-62.

Durojaye, E. (2013). Woman but not Human Widowhood Practices and Human Rights violations in Nigeria. International Journal of Law, Family and Policy 27: 176-196.

Durojaye, E. and Munge, P. (2011). A Holistic Approach to Addressing Female Genital Cutting (FGC) in Africa: The Relevance of the Protocol to the African Charter on the Rights of Women. Akungba Law Journal I: 240-259.

Economic Commission of Africa, (2009). African Women's Report 2009, Measuring Gender Inequality in Africa: Experiences and Lessons from the African Gender and Development Index. Available at: www.uneca.org/eca_resources/publications/books/awr/AWRog_FIN.pdf (accessed on 12 April 2014).

FAO/IP, (2003). HIV/AIDS and agriculture: impacts and responses - Case studies from Namibia, Uganda and Zambia Rome: FAO.

Freidman, S. (1996). Less Equal than others - Equality and Women's Rights. In Gearty C and Tomkins A (eds) Understanding Human Right London and New York: Mansell, pp. 197-212.

Freidman, S. (1999). A Critical Review of the Concept Equality in UK Anti-Discrimination Law' Independent Review of the Enforcement of UK Anti-Discrimination Legislation. Working Paper No 3 Cambridge: Cambridge Centre for Public Law and Judge Institute of Management. 29.

Garcia-Moreno, C. and Watts, C. (2000). Violence against women: its importance for HIV|AIDS. AIDSI4: $253-65$.

Gruskin, S. and Tarantola. D. (200I). Health and Human Rights. In: Detels, R, and Beaglehole, R. (eds) Oxford Textbook on Public Health. New York: Oxford University Press, pp.311-335

International Monetary Report Fund (IMF), (20II). Republic of Mozambique: Poverty Reduction Strategy Paper. Washington DC: IMF.

Institute for Education Development, (2004). New Curriculum for Education. Maputo. Institute for Education Development.

InstitutoNacional de Estatistica (INE), (2007). Population Census. Maputo. INE.

InstitutoNacional de Estatistica, Ministerio da Saude, (2005). Mozambique Demographic Health Survey. Maputo, Moçambique and ORC Macro.

Jewkes, R. Sen, P. and Garcia-Moreno, C. (2002). Sexual Violence. In Krug, E. G. et al. (eds). World Report on Violence and Health Geneva: WHO, pp.147-174.

Jewkes, R. K., Dunkle, K., Nduna, M., Shailntimate, N. (2010). Partner violence, relationship power inequity, and incidence of HIV infection in young women in South Africa: a cohort study. Lancet 376: 41-48.

Jewkes, R. and Morrell, R. (2010). Gender and sexuality: emerging perspectives from the heterosexual epidemic in South Africa and implications for HIV risk and prevention. Journal of International AIDS Society 13: 1-11.

Kilpatrick, D. G. (2004). What is Violence Against Women? Journal of Interpersonal Violence 19: 1209-1234.

Krug, E. G., Dahlberg, L. L. Mercy, J. A., Zwi, A. B. and Lozano, R. (2002). World Report on Violence and Health Geneva: World Health Organization.

Maman, S., Campbell, J., Sweat, M. D., Gielen, A.C. (2000). The intersections of HIV and violence: directions for future research and interventions. Social Science and Medicine 50: 459-78.

Ministry of Planning and Development: National Directorate of Studies and Analysis, (20ro). Poverty and well-being in Mozambique. Third National Poverty Assessment. Maputo: Ministry of Planning and Development.

Minow, M. (1988). Feminist reason: getting it and losing it. Journal for Legal Education 38: 47-60.

Mukasa, R.S. (2008). The African Women's Protocol: Hamessing a Potential Force for Positive Change. Auckland Park: Jacana. 
Mausse, M. and Cunha, N. (20II). Mozambique: Setting Up a Social Protection Floor. In: ILO and UNDP (eds) Sharing Innovative Experiences: Successful Social Protection Floor Experiences New York: UNDP, pp. 313-332.

Nabaneh, S. (2015). Challenges in Litigating the Right to Health in Mozambique: A Critical Analysis. In Durojaye, E. (ed). Litigating the Right to Health in Africa: Challenges and Prospects. London: Routledge, pp.195-218.

Namburete, E. (2009). Southern African Development Community Gender Protocol Baseline Study: Mozambique, available at http://www.genderlinks.org.za/article/sadc-gender-protocolbarometerbaseline-study-mozambique (accessed on 23 April 2016).

Nour, N.M. (2006). Health Consequences of Child Marriage in Africa. Emerging Infectious Diseases Journal I2: $1644-1649$.

Nour, N.M. (2009). Child Marriage: A silent health and human rights issue. Reviews in Obstetrics and Gynaecology 2: 51-56.

Raj, A., Saggurti, N., Balaiahd, D. and Silverman, J. G. (2009). Prevalence of Child Marriage and its Impact on the Fertility and Fertility Control Behaviours of Young Women in India. Lancet 373: 1883-1889.

Save the Children (2007). Denied Our Rights: Children, women and inheritance in Mozambique Rome: Save the Children.

Save the Children (2009). Children and Women's Rights to Property and Inheritance in Mozambique Rome: Save the Children.

Shalev, C. (2000). Rights to sexual and reproductive health: The ICPD and the Convention on the Elimination of All Forms of Discrimination against Women. Health and Human Rights4: 38-66.

Sheldon, K. (2002). Pounders of Grain: a History of Women. Work and Politics in Mozambique. Portsmouth N.H: Heinemann.

Terry, G. (2007). Women's Rights. London: Palgrave Macmillan.

Tvedten, I. (20II). Mozambique country case study: Gender Equality and Development. Washington DC: World Bank.

UNAIDS (2014). Mozambique HIV Epidemic Profile Maputo: UNAIDS

UNAIDS and WHO (2005). AIDS Epidemic Update Geneva: UNAIDS.

UNFPA and UNICEF (2015). Child Marriage and adolescent pregnancy in Mozambique: Causes and impact. Maputo: UNFPA and UNICEF.

UNICEF (2007). Protecting against abuse, exploitation and violence: Child Marriage. Available at: http://www.unicef.org/progressforchildren/2007n6/index_41848.htm (accessed on 1o May 2016).

UNICEF (2013). Ending Child Marriage Progress and Prospect. New York: UNCIEF

United Nations Development Programme (2015. Human Development Report: Work for Human Development New York: UNDP.

UNIFEM (2007). Violence against Women in Mozambique New York: UNIFEM.

United Nations Department of Economic and Social Affairs, Population Division (2008). World Marriage Data New York: United Nations.

Urdang, S. (1998). And Still They Dance: Women, War and the Struggle for Change in Mozambique. London, Earthscan.

US Department of State (2010). 2009 Country Reports on Human Rights Practices: Mozambique. Available at http://www.state.gov/g/drl/rls/hrrpt/200g/af/135967.htm,(I5 (Accessed on I5 May 2016).

World Economic Forum (2015). The Global Gender Gap Report 2015. Available at: http://www3.weforum.org/docs/WEF_GenderGap_Report_20II.pdf (accessed I2 September 2016). 